\title{
A Pedagological Study Of Intrinsic Motivation In The Classroom Through Autonomy, Mastery, And Purpose
}

Sarah Gillard, M.S.Ed., Purdue University North Central, USA

Sharlett Gillard, Ed.D., University of Southern Indiana, USA

David Pratt, Ph.D., Purdue University North Central; USA

\begin{abstract}
Increasing regulation imposed on education systems at all levels engulfs teaching/learning time and impedes individual pursuits of interest to the learner. However, by restructuring the way educators approach the classroom, students can be provided an opportunity to explore further and become more successful. This success can be derived by removing extrinsic motivation from the equation, leaving the student to rely on intrinsic motivation through autonomy, mastery, and purpose. Described herein is an experimental Master's level Educational Psychology course structured and conducted following these guidelines.
\end{abstract}

KEY WORDS: Autonomy; Intrinsic Motivation; Purpose; Pedagogy

\section{INTRODUCTION}

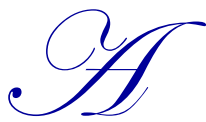

s our education system continues to be increasingly regulated, students are being made to fit into political, cookie-cutter expectations. At every level of education, demands for outcomes such as higher scores on standardized tests and higher attendance, retention, and graduation rates are forcing administrators to micromanage the teachers under their charge, who, in turn, are micromanaging the students in his or her classroom.

While micromanaging may seem positive in theory, it does not play out well in practice. Students are being micromanaged right into mediocrity, with the average-ability student becoming the common denominator. Highaverage- nor low-ability students are well served. (Deci, 1972.)

High-ability students are not encouraged to individually pursue personal interests. There is no time for independent study, as the classroom must adhere to a strict schedule of subjects taught at specific times. Averageability students are best able to fit the cookie-cutter expectations; however, all creative thought and pretense are pushed to the side as students go through every hoop set for them in hopes of earning a passing grade. (Lepper, 1973.) Low-ability students are forced to try to keep up with the rest of the class. There is little or no time allotted for missed or misunderstood material, leading to holes in their fundamental academic structuring and framework. (Harlow, 1953.)

\section{MOTIVATION FOR EXPERIMENT}

What if this micromanaging came to a halt? What if an obscure and different teaching philosophy was adopted? These questions were explored in the book, Drive: The Surprising Truth About What Motivates Us, by Daniel Pink. His motivation theory, which is based on fifty years of behavioral scientific findings published by researchers around the world, can be divided into three distinct parts: Autonomy, Mastery, and Purpose (Pink, 2009). 
Merriam-Webster defines autonomy as, "the state of existing or acting separately from others: the power or right of a country, group, etc., to govern itself." (Merriam-Webster, 2013). When one is autonomous, one is free to think for his or herself, with no concern as to others' rules and regulations. Pink theorizes that there is a hidden drive in human beings to be autonomous in their work; that by having autonomy, people will work harder and at a much higher level, giving more of themselves.

Mastery is defined as the "knowledge and skill that allows you to do, use, or understand something very well." (Merriam-Webster, 2013). Pink explains that once a person is autonomous, they will have the desire to gain mastery over the topic at hand. They will feel free to become engaged with their work, thus entering them into the state of Flow. This state of Flow is a mental state in which a person becomes entirely focused and energized by the task at hand. It has been found that in this state, people do their best work. (Csikszentmihalyi, 1990.)

The third element of Pink's motivation theory, purpose, is defined as "The reason why something is done or used: the aim or intention of something" (Merriam-Webster, 2013). While a person with a sense of autonomy and mastery is able to grow and reach new heights, according to Pink, if that same person has gained a sense of purpose, even more can be accomplished.

Pink asserts that an individual will exceed every expectation if given autonomy; that the time, effort and money needed to gain mastery of a skill or situation will be willingly invested; that a person given a purpose for doing something, no matter how mundane, will do the job to the best of her or his ability. Nordgren (2013) lends support to the theory by his assertion that through being able to explore and work at one's own pace, for the sheer pleasure of learning, students are better able to obtain mastery of the content area. Challenging students to reach higher and investigate deeper into possible outcomes and higher level thinking can engage students, building their self esteem, and leading to a self-fulfilling prophecy of success. Reeve (2005) injects an interesting parameter to the discussion by asking why motivation is directed towards some goals, yet away from others. Pink seems to advocate that autonomy in any situation will prompt a motivation to achieve beyond expectations. Could the answer to Reeve's query be that motivation is directed to goals where autonomy is provided in the pursuit? Is the theory applicable to all endeavors? Is it applicable to all levels to education?

In a study conducted by Pulfrey, Darnon, and Butera (2013), results of the effect of grades (reward) as a motivational factor vs autonomy to complete the task without grades, revealed that both reward and autonomy had a statistically significant effect on task interest as well as on continuing motivation for the task (desire to do more of the task in their free time). Results further revealed that task performance nor grade results (high or standard grade) predict continuing motivation for the task, whereas perceived task autonomy does. According to their research, "...perceived task autonomy plays the main mediational role in the relationship between grading context and continuing task motivation".

\section{EXPERIMENTAL SETTING}

Pink (2009) discusses teachers implementing his motivational theory in the K-12 classroom setting. However, classroom regulation is not confined to the K-12 environment. Educators in post high school institutions are also being subjected to ever-increasing levels of regulation and micro management by forces such as legislators wanting to justify budgetary allocations and well-meaning administrators attempting to validate and improve their industry standing. Thus Pink's motivational theory should have equal credibility when applied to classrooms of higher education. To test that theory, these researchers applied the concepts to a Master's-level Advanced Educational Psychology course, modifying it to fit Pink's theory that if given the opportunity, people will rise above and beyond expectations set forth.

The course objectives were to acquire a solid foundation of knowledge based on theory and research in the field of educational psychology, to understand the strengths, weaknesses, and classroom implications of new developments in psychology and education, to make the learning of the principles of educational psychology meaningful by relating them to applications in a typical classroom, and to develop an appreciation for the value of reflection in the teaching/ learning process. The students consisted mainly of classroom teachers, all of whom had been through traditional classroom training. 
In keeping with Pink's motivational theory, the conventional textbook was replaced with the trade book, Drive. An Educational Psychology Wikibook was offered as a reference tool. As this was a hybrid class, optional course meeting times were offered, once a week for three hours per meeting. Assignments were given, but no firm due dates were set. The only parameters for the class were that every student regularly participate in Blackboard online discussions and submit all assignments by the last day of class.

To ensure autonomy, students were given choices in every way conceivable. These choices included if and when to attend face-to-face class time, when to complete and submit assignments, which assignments to select from a suggested list, and which topics to undertake for the "Connections to Educational Psychology" pieces.

Online discussion boards were utilized for both teacher- and student-led discussions. As the course progressed, more and more students started conversations and discussions about the material that they were reading, wanting to gain mastery of topics for themselves.

\section{RESULTS OF EXPERIMENT}

While this method seems to fly in the face of traditional pedagogical and andragogical approaches, research results say otherwise. The course designers asked this group of professionals to stretch and grow in an atypical course, and most found it to be refreshing and exciting, providing each student a new perspective on how to educate the youth of our nation. Results were gleaned from surveys given midterm, and at the end of the course. (See Appendices.) These surveys were administered by the course instructor online with all responses given anonymously.

Individual course work showed the most growth from the autonomy that this course afforded each student. Attendance was at, or above, expected levels throughout the course. By giving students the autonomy to choose for themselves if they were going to attend class, intrinsic motivation became the primary motivation.

The idea of intrinsic motivation setting the stage for the students in the course seemed groundbreaking. Students would get out of this course what they put into it. What was found, was that, if given a choice, students were willing to do much more work on their own towards mastery of a subject than if told exactly what to do, how to do it, and when to turn it in. Assignments were more in-depth. Papers were longer. Students became, and stayed, engaged in the subject matter. The course no longer was just another item on the to-do list to be checked off before graduation. It became an opportunity to test oneself; to grow intellectually; to engage with others of the like mind; to enter the state of Flow.

To aid in evaluating the success of the experiment, two questionnaires were administered; one at midsemester and at the conclusion of the semester. Both were provided via Blackboard, but students were allowed to respond anonymously by any method they wished. At the conclusion of the course, $92.3 \%$ of the participants agreed or strongly agreed that the course challenged them to think, stretched and broadened their views greatly, and that the teaching methods were well chosen. All participants-100\%--indicated that this course was worthwhile and gave opportunities to develop more original ideas for the classroom

\section{CONCLUSION AND RECOMMENDATION}

Traditionally, classroom teachers (especially at the college level) were primarily dispensers of knowledge. But teachers are no longer the primary source of information since anyone, anywhere has easy access to online information. Teachers, then, can no longer only be dispensers of knowledge. With the help of technology, students are changing. They are learning differently and are accessing information differently. Thus in recent years, many teachers have become facilitators of learning. However, educators can no longer only be facilitators of learning either. Learning more and more information does not matter unless that information becomes purposeful and makes sense to the student. Therefore, it is now time to advance to the next level: teachers must become motivators of purpose. 
As a motivator, a teacher is no longer in complete control over what, or how, a student learns. Control must be given, at least in part, to the student so that he or she is freely able to master that knowledge important to his or her purpose. (Johnson, 2005).

The success of this course study leads to the question, what would happen if educators structure more classrooms in this way? What great happenings would occur if our youth were provided more choices in what they learn, how they learn and when they learn? Instead of enforcing strict rules and regulations on every teacher in every public school, what might happen if each teacher was allowed a bit of autonomy with their classroom and pupils?

Plausible answer: Students would be allowed to follow their interests. The intrinsic motivation that lies within each student would be awakened. Motivation 3.0 would have the opportunity to kick in, and from this, greatness could ensue. If more schools were allowed to operate under Pink's Motivation 3.0 philosophy, more students would obtain Autonomy, Mastery, Purpose, and ultimately, Flow. More schools would possibly find an increase in attendance, in grades, and in good behavior. Personal success and engagement would be set to increase dramatically.

Instead of micromanaging students into mediocrity, educators need to set the course for individual achievement. No two students are the same. Everyone needs to be able to strive for his or her own personal greatness, following his or her own personal goals.

\section{AUTHOR INFORMATION}

Sarah A. Gillard was a researcher at Purdue University North Central at the time of this study. Sarah earned her Master's in Elementary Education and is pursuing her doctoral degree in Educational Psychology. Sarah is particularly interested in the way intrinsic motivation is used in the classroom. E-mail: s.gillard@hotmail.com

Sharlett Gillard is a Professor of Computer Information Systems at the University of Southern Indiana. Throughout her career she has been interested in numerous, diverse education issues at all levels of the teaching/learning experience, which has led to collaboration with professionals in various disciplines. E-mail: sgillard@usi.edu. Corresponding author.

David Pratt has recently completed 12 years as an instructor of elementary education in the education department at Purdue University North Central campus. He specializes in teaching graduate and undergraduate courses in educational psychology, educational technology and assessment. He served as a public school teacher for 10 years in California before receiving his Ph.D. in Educational Psychology at the University of California, Santa Barbara in 2002. Email: Dpratt@pnc.edu

\section{REFERENCES}

1. (2013) “Autonomy," “mastery," and "purpose.” Merriam Webster. Retrieved 11/12/13 from http://www.merriam-webster.com/dictionary/...

2. Csikszentmihalyi, M. (1990). "Flow: The Psychology of Optimal Experience." Harper \& Row. New York.

3. Deci, E. L. (1972). "Intrinsic Motivation, Extrinsic Reinforcement, and Inequity." Journal of Personality and Social Psychology. 22(1) 113-120

4. Harlow, H. F. (1953). "Motivation as a Factor in the Acquisition of New Responses." Current Theory and Research on Motivation. Lincoln: University of Nebraska Press.

5. Johnson, B. C., Manyika, J. M., and Yee, L. A. (2005). "The Next Revolution in Interaction.” McKinsey Quarterly. 4 25-26.

6. Lepper, M., Green, D., and Nisbett, R. (1973). "Undermining Children's Intrinsic Interest with Extrinsic Rewards: A test of the 'Overjustification' Hypothesis." Journal of Personality and Social Psychology. 28(1) 129-37. 
7. Nordgren, R.D. (2013) 'Pink's 'Motivation 3.0' and Student Centered Schooling: Creating Life-Long Learners for the $21^{\text {st }}$ Century." Journal of Research In Innovative Teaching. 6(1) 3.

8. $\quad$ Pink, D. (2009). Drive: The Surprising Truth About What Motivates Us. Riverhead Books. New York.

9. Pulfrey, C., Darnon, C., and Butera, F. (2013). “Autonomy and Task Performance: Explaining the Impact of Grades on Intrinsic Motivation." Journal of Educational Psychology. 105(1) 39-57.

10. Reeve, J. (2005). Understanding Motivation and Emotion. $4^{\text {th }}$ ed. Hoboken, N.J. John Wiley \& Sons. 


\section{NOTES}

